\title{
INCORPORACIÓN DE MECANISMOS DE COOPERACIÓN JUDICIAL INTERNACIONAL EN LA LEGISLACIÓN PENAL ECUATORIANA
} INCORPORACÃO DE MECANISMOS DE COOPERAC $\tilde{O}$ JUDICIÁRIA INTERNACIONAIS NA LEGISLAÇẢO PENAL ECUATORIANA

Bolívar Augusto Espinoza*

Resumen: El presente artículo pretende dar a conocer brevemente la forma de regulación en la legislación penal ecuatoriana de los mecanismos de cooperación jurídica internacional; específicamente la asistencia penal internacional, todo esto como un elemento determinante para lograr una persecución penal de alta calidad; contiene además un breve análisis de la norma jurídica dispuesta en el Código Orgánico Integral Penal, en contraste a las normas contempladas en la Convención de Naciones Unidas contra la Delincuencia Organizada Transnacional y la Convención Interamericana de Asistencia Mutua en Materia Penal.

Resumo: Este artigo pretende descrever brevemente a forma de regulamentação na legislação penal equatoriana dos mecanismos de cooperação jurídica internacional; especificamente a assistência criminal internacional, tudo isso como um fator determinante para alcançar uma ação penal de alta qualidade; também contém uma breve análise da norma legal estabelecida no Código de Integridade Criminal, em contraste com as normas contempladas na Convenção das Nações Unidas contra o Crime Organizado Transnacional e a Convenção Interamericana sobre Assistência Mútua em Matéria Penal.

Palabras clave: Mecanismos de cooperación judicial, Asistencia mutua en materia penal, Convención Interamericana de Asistencia Mutua

Palavras-chave: Mecanismos de cooperação judiciária, Assistência mútua em matéria penal, Convenção Interamericana sobre Assistência Mútua

* Fiscalía General, Ecuador.

E-mail: bolivar.espinoza@gmail.com

Recibido: 04/09/2017. Aceptado: 29/09/2017. 


\section{INTRODUCCIÓN}

La creciente interdependencia en la sociedad globalizada, ha dado origen a un incremento de la delincuencia organizada, lo que ha obligado tanto a los sistemas estatales a través de los órganos judiciales y policiales a generar mecanismos de respuesta inmediata y eficaz, en lo que respecta a la persecución y judicialización penal de este tipo de delitos. Así esta realidad actual, sumado a otros factores como lo son: a) La frecuente movilidad de las personas, la cual ha dado origen a un constante requerimiento y exigencia de acceso a la justicia, reclamando auxilio de otras autoridades judiciales extranjeras, ya sea para ejecutar la práctica de un acto procesal destinado a fortalecer un proceso penal ya iniciado o simplemente coordinar alguna actividad investigativa policial en el extranjero; b) La libre circulación de capitales que origina el blanqueo o lavado de dinero y, c) La proliferación de procesos penales originados por delitos provenientes de delincuencia organizada transnacional, los cuales presentan un importante componente internacional, generan la porque no decirlo en la mayoría de los casos, la necesidad de reclamar un auxilio judicial siendo este, la solicitud de asistencia en materia penal.

El presente trabajo, pretende mencionar brevemente, dos instrumentos internacionales que contemplan y abordan la cooperación judicial, esto es la solicitud de asistencia penal internacional entre los principales; sus cuestiones prácticas y el rol de la Autoridad Central, que para el presente caso, dicha encomienda le corresponde a la Fiscalía General del Estado ecuatoriana; adicionalmente explicaremos la incorporación en la normativa penal interna ecuatoriana - Código Orgánico Integral Penal- el mecanismo de auxilio judicial, y su impacto en el proceso penal.

\section{INSTRUMENTOS INTERNACIONALES QUE CONTEMPLAN LA SOLICITUD DE ASISTENCIA PENAL INTERNACIONAL}

Mención especial merece, para efectos de desarrollo de la presente premisa, enunciar dos instrumentos claves, las cuales dan origen a una conceptualización de lo que consiste la asistencia penal internacional, esto es la Convención de Naciones Unidas Contra la Delincuencia Organizada Transnacional -en el ámbito multilateral- y la Convención Interamericana de Asistencia Mutua en Materia Penal, desde la perspectiva regional o hemisférica.

En lo referente a la Convención de Naciones Unidas contra la Delincuencia Organizada Transnacional, o más conocida como la Convención de Palermo, tiene como principal objeto promover la cooperación jurídica para prevenir y combatir más eficazmente la delincuencia organizada transnacional, esta Convención para el 
quehacer de la Autoridad Central, que en el caso ecuatoriano, es la Fiscalía General del Estado, es de especial relevancia por la gran cantidad de herramientas que presta para desarrollar una prolija labor investigativa con especial énfasis a la criminalidad organizada transnacional.

Así, el artículo 18 de la referida Convención de Palermo, contempla que, en relación a la asistencia judicial, es una exigencia que se impone a los Estados Parte para que presten "la más amplia asistencia judicial recíproca respecto de las investigaciones, procesos y actuaciones judiciales" relacionada con los delitos materia de la Convención.

Si bien es cierto, desde un enfoque analítico, el término incorporado dentro de la Convención, es "judicial” podría entenderse que únicamente se ajusta al órgano jurisdiccional como tal, no obstante puede ser interpretado desde un sentido más amplio, esto es no solo desde la colaboración entre jueces sino también entre fiscales a nivel internacional.

La referida Convención de Palermo, aporta dos elementos importantes para este tema, esto es los requerimientos de la asistencia y la forma de gestionarla, aborda también la posibilidad de traslado de testigos o imputados de un país a otro para fines relacionados con la investigación o una actuación judicial. Precisa las causales de denegación de asistencia y las formas en que se cubren los gastos de la asistencia. Se destaca expresamente que los Estados Parte no pueden invocar el secreto bancario para denegar la asistencia requerida, siendo éstos los principales aspectos.

En relación a la Convención Interamericana de Asistencia Mutua en Materia Penal, es un instrumento que con una mayor claridad define los lineamientos en que los Estados Parte, deberán prestarse asistencia mutua en investigaciones, juicios y actuaciones en materia penal referentes a delitos cuyo conocimiento sea de competencia del Estado requeriente al momento de solicitarse la asistencia.

Dentro de este contexto, sobre la Convención Interamericana de Asistencia Mutua en Materia Penal, es necesario principalmente, interpretarla desde dos enfoques de utilidad.

El primer enfoque acerca de la modalidad de asistencia judicial para la obtención de la prueba testimonial o pericial; y, el segundo enfoque acerca del traslado temporal de detenidos.

Así en referencia al primer enfoque, esto es acerca de la modalidad de asistencia judicial para la obtención de la prueba testimonial o pericial, la Convención, en su artículo 18, regula la posibilidad de que la prueba se obtenga a través de la declaración testimonial prestada en el territorio del Estado requerido; y, que la declaración del testigo o el informe del perito pueda emitirse en el Estado requirente, posibilitando el desplazamiento de la persona al territorio de éste.

Generalmente desde la práctica, la primera de las posibilidades es la más frecuente, y tiene como ventaja que no se necesita el 
consentimiento del testigo o perito para acceder a la solicitud. En estos casos se requiere que la solicitud de asistencia se acompañe listados de preguntas que tienen que ser formuladas al testigo o el perito. Siendo esta una práctica sencilla, pero es la que menos se ajusta a los principios que han de regir la prueba, pues afecta el principio de inmediación en la recepción por parte de quien deberá apreciarla y valorarla; pero esta objeción podría solventarse, cuando la autoridad competente se traslade al lugar para presenciar e intervenir en la misma, posibilidad que contempla en el artículo 16 de la Convención, cuando claramente expresa que: "las autoridades y las partes interesadas, o sus representantes, del Estado requirente, podrán previo conocimiento de la Autoridad Central del Estado requerido, estar presentes y participar en la ejecución de la solicitud de asistencia en la medida en que no lo prohíba la legislación del Estado requerido y haya expreso consentimiento de sus autoridades al respecto". Otro mecanismo para solventar este pequeño obstáculo sería a través de la videoconferencia, la cual es una solución rápida y efectiva.

Es necesario destacar otra de las importantes modalidades que contempla la Convención para la práctica de actos procesales destinados a recabar el testimonio de un testigo o de un perito, se pueda ejecutar en el propio Estado requirente, lo que facilitaría que la práctica se lo haga de acuerdo a la normativa interna del país requirente, pero además con el valor agregado que no se afectaría el principio de inmediación en el propio acto del juicio. Para esto es necesario contar con la conformidad del testigo o perito y no podrán emplearse medidas coercitivas; la Convención, para desarrollar esta posibilidad, en el artículo 22 contempla la posibilidad del salvoconducto, de modo que facilitaría que, si una persona acude a colaborar a otro Estado en calidad de testigo o perito, ésta, no podrá ser detenida o enjuiciada por delitos anteriores a sus salidas del territorio del Estado requirente. No podrá ser requerida para declarar o dar testimonio en procedimientos no especificados en la solicitud; $y$, no podrá ser detenida o enjuiciada con base a la declaración que preste, salvo en casos de perjurio o falso testimonio.

En relación al segundo enfoque acerca de la novedosa posibilidad de que la Convención Interamericana de Asistencia Mutua en materia Penal, contempla la posibilidad de prestar asistencia para la obtención de declaraciones de personas detenidas en el Estado requerido, se refiere específicamente en los artículos 20 al 22.

Es en estos casos, donde la práctica de la asistencia es más compleja, pues no solo se trata de cooperar en la obtención de una prueba sino también en el traslado de una persona privada de libertad. Además de ello habría que unir que la declaración de la persona detenida, es un mecanismo para garantizar el derecho a la defensa, de modo que es complejo que la declaración de la persona aprehendida pueda tomarse como la de un testigo; pues esta declaración exige de la 
práctica de garantías concretas, y de no aplicarlas se estaría vulnerando sus derechos fundamentales.

Para lograr proceder el traslado temporal de la persona que se encuentre detenida o condenada, se necesitará de dos consentimientos claves, esto es del Estado requerido, donde se encuentra privado de libertad y el otro del propio detenido, pues así lo contempla el artículo 20.

Así, la Convención contempla una serie de causas de denegación de la solicitud de traslado temporal, en los casos de que su presencia fuera necesaria en una investigación o en un proceso penal pendiente en la jurisdicción a la que se encuentra sujeta la persona. Pero si se cumplen todos los requisitos para que el traslado pueda producirse el Estado requiretente se comprometerá con el cumplimiento de una serie de obligaciones y a respetar ciertas limitaciones. El Estado tendrá la obligación de mantener bajo custodia física a la persona trasladada a menos que el Estado remitente indique lo contrario. Asimismo, se comprometerá a retornar a la persona trasladada al Estado que la envió tan pronto con las circunstancias lo permitan con sujeción a lo acordado entre las autoridades centrales de ambos Estados para que al regreso de la persona trasladada se pueda exigir el seguimiento de un procedimiento de extradición.

\section{ROL DE LA AUTORIDAD CENTRAL ECUATORIANA, LA FISCALÍA GENERAL DEL ESTADO, FRENTE A LA COOPERACIÓN JUDICIAL INTERNACIONAL}

Corresponde por mandato constitucional a la Fiscalía General del Estado de Ecuador, dirigir de oficio o a petición de parte, la investigación preprocesal y procesal penal; durante el proceso ejercerá la acción pública con sujección a los principios de oportunidad y mínima intervención penal.

Bajo esta premisa jurídica, la intervención, en el ámbito de la cooperación mutua en materia penal, la atribución de la Fiscalía General del Estado, es reciente, pues es a raíz del año 2003, que tras la suscripción por el Estado ecuatoriano, de la Convención de Asistencia Mutua en Materia Penal y de la Convención de Palermo (Convención de Naciones Unidas contra la Delincuencia Organizada) la Fiscalía General del Estado, cobra un importante papel para la ejecución de estos instrumentos, gracias a su designación en calidad de Autoridad Central para el marco de las referidas convenciones, institución a la cual le corresponde facilitar a través de mecanismos necesarios el auxilio judicial internacional previsto, dentro del ámbito de sus competencias, lo dispuesto en estos dos convenios internacionales.

Así, el 10 de diciembre del 2004, la Fiscalía General del Estado, creó dentro de su organización interna la Unidad de Asuntos 
Internacionales, actualmente Dirección de Asuntos Internacionales y Cooperación, sección que tiene la misión de asesorar, tramitar y realizar el seguimiento a los requerimientos de las autoridades competentes a través de una correcta ejecución y cumplimiento -para este caso- de los requerimientos de asistencia penal internacional.

La Fiscalía General del Estado de la República del Ecuador, a través de la figura de Resolución, signada como No 020-2014-FGE, expidió el Instructivo de Cooperación Penal Internacional, el cual pretende guiar de una forma metodológica el manejo de las solicitudes de asistencia penal internacional, como bien, señala la referida resolución contiene, una breve y descripción de cómo activar este mecanismo de auxilio judicial, en procesos penales que se hayan iniciado en el Ecuador o que han sido solicitados desde el extranjero.

La Fiscalía General del Estado, en ejercicio del rol de Autoridad Central, ha implementado una herramienta técnica informática, la cual pretende asegurar la correcta redacción de una solicitud de asistencia penal; este sistema informático, pretende incorporar en una forma determinada, ciertos parámetros de contenidos básicos que debe reunir para que la solicitud de auxilio judicial para que pueda ser librada al extranjero, guardando relación con los principios procesales de congruencia y uniformidad a la realidad procesal.

Los parámetros, que ha considerado el módulo de solicitudes de asistencia penal, son:
a. Identificación de la autoridad que formula la solicitud;
b. Identificación de la autoridad a la que se propone la solicitud;
c. Objeto y motivo de la solicitud;
d. Datos generales del contexto investigativo que dan origen a la solicitud;
e. Fundamentación jurídica normativa de la solicitud; y,
f. Prioridad señalada de la solicitud.

Laflexibilidadenla redacción delosrequerimientosinternacionales, gracias a esta herramienta automatizada por la Fiscalía General del Estado, ha permitido disminuir graves problemas de entendimiento entre las autoridades judiciales de los Estados implicados, pues si bien es cierto, la gran diferencia en normativa interna y sistemas procesales, ha permitido coincidir en disposiciones claves tanto de las Convenciones ya señaladas anteriormente, esto es Convención de Naciones Unidas contra la Delincuencia Organizada y la Convención Interamericana de Asistencia mutua en Materia Penal. 


\section{INCORPORACIÓN EN LA NORMATIVA INTERNA ECUATORIANA DEL MECANISMO DE AUXILIO JUDICIAL INTERNACIONAL Y SU IMPACTO DENTRO DEL PROCESO PENAL}

El Código Orgánico Integral Penal, es específicamente en losa 485, 486, 488, 496 y 497, donde incorpora determinadas herramientas investigativas, para fortalecer la persecución penal de determinados delitos que presenten un componente de crimen organizado transnacional.

Esta remisión y armonización de la normativa interna ecuatoriana, frente a la Convención de Naciones Unidas contra la Delincuencia Organizada, es un importante avance para el desarrollo del sistema jurídico penal.

Dichas disposiciones legales, que constan dentro del Código Orgánico Integral Penal, definen e incorporan diferentes figuras jurídicas, por ejemplo: i) la entrega vigilada o controlada y su procedimiento para ejecutarla, ii) la remisión de procedimientos probatorios; iii) las investigaciones conjuntas; $y, i v$ ) el que será objeto de nuestro análisis, la solicitud de asistencia judicial recíproca.

El artículo 497 del COIP, es una disposición que precisa a mayor detalle y técnica jurídica, esta especial innovación jurídica con alto impacto dentro de la ejecución del proceso penal, la disposición pretende dar una definición conceptual de lo que se entiende por Asistencia Judicial Recíproca, a continuación, daremos un vistazo a la norma jurídica:

Las o los fiscales podrán solicitar asistencia directa a sus similares $\mathrm{u}$ órganos policiales extranjeros para la práctica de diligencias procesales, pericias, einvestigación de delitos previstos en este Código. Esta asistencia se refiere entre otros hechos, a la detención y remisión de procesados y acusados, recepción de testimonios, exhibición de documentos inclusive bancarios, inspecciones del lugar, envío de elementos probatorios, identificación y análisis de sustancias catalogadas sujetas a fiscalización e incautación y comiso de bienes.

Asimismo, la o el fiscal podrá efectuar actuaciones en el extranjero dirigidas a recoger antecedentes acerca de hechos constitutivos de alguna infracción, a través de la asistencia penal internacional. Las diligencias señaladas serán incorporadas al proceso, presentadas y valoradas en la etapa de juicio.

Para situar nuestro análisis, esta importante regulación normativa es considerada de gran avance, por dos razones: la primera por cuanto es notorio y evidente la remisión de la norma interna frente a las disposiciones convencionales internacionales, tanto de la Convención Interamericana de Asistencia Mutua en Materia Penal así como de la Convención de Naciones Unidas contra la Delincuencia Organizada 
Transnacional; y, la segunda por el importante impacto procesal que tiene la aplicación del mecanismo de asistencia judicial recíproca al momento que se activa dentro de una investigación penal, toda vez que mejora la calidad de la investigación e indirectamente aplica el principio de la debida diligencia en la investigación penal, estándar exigido para la sustanciación correcta de procesos penales.

Analizando conceptualmente, el Código Orgánico Integral Penal, incorporó en la definición de la asistencia judicial recíproca, determinados elementos como lo son:

a. Que dispone que son los fiscales quienes pueden solicitar la asistencia de una forma directa a sus similares - es decir fiscalías extranjeras- $u$ órganos policiales extranjeros, que para efectos de este análisis, se entendería que se trata de la INTERPOL, AMERIPOL o EUROPOL. Situación que se contrapone con el espíritu de la Convención contra la Delincuencia Organizada Transnacional y porque no decirlo con la Convención Interamericana de Asistencia Mutua en Materia Penal, toda vez que tal como reza del epígrafe de la norma, el concepto "judicial” debe ser interpretado en un sentido amplio, no únicamente para Fiscales, pues no se descartaría recabar elementos en un determinado país donde todavía se encuentre en vigencia el sistema inquisitivo; $y$, sea el Juez quien requiera activar este mecanismo, como por ejemplo en los supuestos jurídicos que demanda la intervención estrictamente judicial.

b. La referida disposición legal, contiene el elemento de que la asistencia estará destinada para practicar diligencias procesales, pero es aquí en este análisis donde surge una duda, sobre ¿Qué sucedería si se requiere una diligencia dentro de una etapa preprocesal?, pues la disposición jurídica, lo que hace es limitar al fiscal a activar el mecanismo de auxilio judicial únicamente cuando la investigación como tal se encuentra configurado como un "proceso" estrictamente penal.

c. La norma objeto de análisis, describe, por así mencionarlo un listado de diligencias que pueden practicarse, entre estas: pericias, investigación de delitos existentes en el COIP, detención, remisión de procesados y acusados, recepción de testimonios, exhibición de documentos -inclusive bancarios-, inspecciones dellugar, envío de elementos probatorios, identificación y análisis de sustancias catalogadas sujetas a fiscalización e incautación y comiso de bienes; situación jurídica que es limitante para el quehacer tanto del fiscal como del órgano jurisdiccional, por dos razones: la primera por cuanto el requisito de doble incriminación es determinante para que proceda la solicitud, esto es que el hecho que origine la solicitud de asistencia, debe ser 
punible en la legislación del Estado requerido; y, la segunda por cuanto el catálogo de diligencias que se detalla en la disposición jurídica es muy limitante frente al amplio espectro de aplicación que contienen las Convenciones de Naciones Unidas contra la Delincuencia Organizada y la Interamericana en Asistencia Mutua en Materia Penal.

d. Con el objeto de concluir este análisis, la norma interna incluyó, en lo principal, que las diligencias serán incorporadas al proceso, presentadas y valoradas en la etapa de juicio, lo que genera un gran impacto probatorio dentro del proceso, específicamente en aquellos delitos que tienen un componente internacional, como lo son en la mayoría de casos, los delitos provenientes de delincuencia organizada transnacional, de ahí la importancia de practicar el mayor número de diligencias existentes y contempladas en las Convenciones ya señaladas.

Tras la breve reflexión realizada anteriormente, es importante, a largo plazo, debido a la gran importancia de este mecanismo de cooperación judicial, que por sus beneficios de activarlo ya se ha señalado, que la disposición jurídica prevista en el artículo 497 del Código Orgánico Integral Penal Ecuatoriano, debe reformularse, con ciertos elementos facilitando a que sea que cualquier operador de justicia en materia penal quien pueda activar los mecanismos de cooperación judicial, entre estos - y para el caso que amerita- la solicitud de asistencia judicial recíproca, ante las autoridades competentes internacionales, por intermedio de la autoridad central designada para el efecto.

Esta asistencia judicial podrá consistir, en solicitar las diligencias o actuaciones constantes en los instrumentos internacionales suscritos en la materia, los cuales una vez hecho serán incorporados a la investigación previa o proceso penal.

El momento procesal para activar dicho mecanismo, será aquel que permita recabar tanto los elementos de convicción relacionados con los hechos fácticos que se investigan o cuando esté destinado a asegurar la presentación de la evidencia dentro de la etapa de juicio.

Huelga decir, que la forma de presentarlo y activarlo, no deberá resumirse en un solo artículo, sino que deberá estar incorporado dentro de los lineamientos de la norma interna ecuatoriana, es decir en el Código Orgánico Integral Penal.

\section{CONCLUSIONES}

Una de las principales conclusiones, resultado de este análisis, tiene que ver con la efectividad de la cooperación judicial internacional, la cual no responde a una cortesía internacional, sino a una obligación 
legal para los Estados que han suscrito las Convenciones antes señaladas; y de ahí radica la necesidad de que tanto los Estados y espacios de integración regional, promuevan y fortalezcan las posibilidades de generar cooperación judicial efectiva, garantizando la tutela judicial efectiva de los ciudadanos en general, el cual se ve proyectado a través de un adecuado desarrollo del sistema procesal penal.

Otro aspecto a destacar, es la amplia posibilidad que ofrece tanto la Convención de Naciones Unidas contra la Delincuencia Organizada así como la Convención Interamericana de Asistencia Mutua en materia penal, para la aplicación de herramientas procesales claves destinadas a mejorar la calidad de la persecución penal en delitos con componente internacional.

Desde la perspectiva de la normativa interna ecuatoriana, el reto está en reforzar la norma jurídica prevista en el artículo 497, con premisas claras, objetivas y directas que lleven a entender el verdadero espíritu de la asistencia judicial recíproca así como el procedimiento para ejecutarla ante la Autoridad Central competente.

Por último, el nudo crítico que pudiese presentarse, podría ser la vulneración de determinados derechos a las partes procesales en la práctica de la solicitud de asistencia judicial recíproca, de ahí la importancia de cuidar y armonizar tanto las legislaciones internas de los países a nivel regional, así como definir un catálogo de las diligencias a practicarse enfocadas con el debido proceso y derechos fundamentales.

\section{REFERENCIAS BIBLIOGRÁFICAS}

Código Integral Penal de Ecuador, 2015.

COMISIÓN EUROPEA. Estudios sobre cooperación jurídica, auxilio judicial internacional y extradición en materia de tráfico de drogas y otros delitos relacionados entre la Unión Europea y sus Estados Miembros y los Países de América Latina y el Caribe, 2013.

Constitución de la República de Ecuador, 2014.

CONVENCIÓN DE LAS NACIONES UNIDAS CONTRA LA DELINCUENCIA ORGANIZADA TRANSNACIONAL. R.O/197, de 24 de octubre del 2003.

CONVENCIÓN INTERAMERICANA DE ASISTENCIA MUTUA EN MATERIA PENAL. R. O/147, de 14 agosto, 2003.

ESPINOZA, B. Breve Exposición de la Regulación en el derecho interno ecuatoriano de la solicitud de asistencia penal internacional. Preparado para la UTPL, 2015.

FISCALÍA GENERAL DEL REINO DE ESPAÑA. Memorias de la 
Fiscalía de Cooperación Internacional. Madrid: 2013.

\section{RESUMEN BIOGRÁFICO}

Bolivar Augusto Espinoza es Abogado por la Universidad Central del Ecuador. Especialista en Derecho Penal, Universidad Andina "Simón Bolívar". Maestría en Diplomacia y Relaciones Internacionales en la Escuela Diplomática de Madrid. Diplomado por la OEA en el Curso Anual de Derecho Internacional, Brasil. Estudios en Derecho Penal Internacional por la Escuela de Verano de la Universidad de Göttingen, Alemania. Visitante profesional en la Fiscalía General del Reino de España - Fiscalía Especializada de Cooperación Internacional- y en la Corte Interamericana de Derechos Humanos -Costa Rica- Formación en la Escuela de la Magistratura París en Cooperación Judicial y Delincuencia Organizada. 